\title{
La ética periodística en el tratamiento de la pobreza
}

María José RUBIO*

Ha llegado el momento de poner fin a la pobreza ${ }^{1}$. Esta es la primera generación de seres humanos que podría erradicar la pobreza extrema de la faz de la tierra. $\mathrm{O}$ al menos en eso confía Jeffrey Sachs, uno de los economistas más importantes del mundo. Para ello, tendrán que sucederse, eso sí, una serie de afortunados eventos, que en síntesis, suponen sistemas políticos y económicos, desarrollo de la ciencia y tecnología, y procesos de cooperación internacional que "miran" constantemente a la pobreza.

Erradicar la pobreza extrema en 20 años no parece demasiado ambicioso si todo el mundo está pendiente de realizar aquello. En otras palabras, es una cuestión de voluntad, a diversos niveles.

¿Es posible que tal ejercicio planetario de la voluntad para erradicar la pobreza extrema se produzca sin la contribución de los medios de comunicación?

En una sociedad en pleno proceso de globalización y uso de nuevas tecnologías de información, esto parece impensable. Ahora bien, que los medios de comunicación no "muestren" y las audiencias no "miren" las noticias sobre las hambrunas producidas por la pérdida de las cosechas que acarrean las variaciones climáticas en el África subsahariana y sobre la desprotección en que se encuentran millones en ese continente, es una cosa muy distinta y se vincula nuevamente a la voluntad.

La realidad mundial del tráfico informativo es similar en todos los países incluido Chile. En la numerosa familia de las noticias, la pobreza es la pariente pobre.

El año 2005, junto con la desigualdad y gracias a las elecciones presidenciales, la pobreza fue noticia en nuestro país. La inclusión en el discurso político de ambos conceptos, tiene coletazos hasta hoy.

El presente artículo insiste no sólo en la ética que supone el mandato de ejercer el periodismo con excelencia, sino que demanda la necesidad de la especialización de los profesionales en el tema del desarrollo social y la pobreza, como eje de una posible contribución de los medios a la reducción de este mal, pero también como una oportunidad real de satisfacer los objetivos que los mismos medios imponen a sus periodistas: ser preferidos por sus lectores y sus audiencias.

Pero, ¿por qué estaríamos llamados los periodistas a contribuir con la erradicación de la pobreza? ¿Existe verdadera pobreza en nuestro país o este es un problema exótico y propio de naciones lejanas con institucionalidad débil, líderes corruptos y carencia de recursos naturales y capital humano? "Suprimir la pobreza a escala mundial constituye una responsabilidad global que reportará beneficios a todo el planeta. Ningún país puede hacerlo por sí solo"2, sostiene Sachs, pero claramente el economista alude a la situación de algunos países africanos y asiáticos que muestran un grave retroceso en el cumplimiento del Objetivo $\mathrm{N}^{\circ} 1$ del Milenio ${ }^{3}$. Es así como en el mundo

\footnotetext{
* Periodista y Licenciada en Comunicación Social de la Universidad de Chile. Fundación para la Superación de la Pobreza.

${ }^{1}$ SACHS, Jeffrey. "El fin de la pobreza. Cómo conseguirlo en nuestro tiempo". Editorial Debate. Buenos Aires. 2006. Pag. 502.

2 Ibid. Pag. 454.

${ }^{3}$ La Declaración del Milenio, que contiene los Objetivos de Desarrollo del Milenio, fue firmada el año 2000 por los miembros de la Organización de Naciones Unidas, incluyendo a Chile, en una cumbre que reunió a 146 jefes de Estado. Establece un conjunto de objetivos de desarrollo que los países deben alcanzar el año 2015 con base en estadísticas de 1990, el primero de los cuales es Erradicar el Hambre y la Pobreza. Disponible en http://www.cepal.org.
} 
globalizado "los pobres" tienen distinto rostro según ubicación geográfica y características de su entorno sociocultural, y también viven diversos problemas urgentes y condiciones de vida precarias.

En Chile, la pobreza se mide por ingresos y en términos absolutos, es decir, a partir del valor en pesos de una Canasta de Satisfacción de Necesidades Básicas ${ }^{4}$ se fija una línea de pobreza, una división estadística e imaginaria entre pobres y no pobres. Quienes obtienen mensualmente igual o menor valor que el fijado por la línea de pobreza son considerados pobres, quienes obtienen aún menos, caen en la indigencia (apenas tienen cómo alimentarse) y quienes obtienen un poco más son casi pobres, pues están al filo del descenso.

El instrumento mediante el cual se realiza esta medición se denomina Encuesta de Caracterización Socioeconómica Nacional (CASEN) y es aplicada por el ministerio de Planificación. De acuerdo con la última medición realizada en 2003, en Chile un 18,8\% de la población se encuentra en situación de pobreza. Este porcentaje representa aproximadamente a tres millones de personas que no pueden satisfacer sus necesidades básicas alimentarias y no alimentarias, de acuerdo con una canasta elaborada con productos que responden a patrones de consumo de la década de los ochenta.

Así, frente al creciente interés de la sociedad por profundizar en las raíces del fenómeno de la pobreza exige a los medios de comunicación y a los periodistas entender la magnitud de esta temática y los alcances de su tratamiento medial. Esto, porque tenemos una política pública con respecto a qué es la pobreza y la medición de ésta la vincula directamente al ingreso económico de las personas. Esta vinculación puede restringir el tratamiento del tema en los medios de comunicación a su comprensión puramente material. Una reflexión que vale la pena hacer para considerar la complejidad de un fenómeno, cuya cobertura periodística requiere el manejo de conceptos y herramientas específicos.

La Fundación para la Superación de la Pobreza ${ }^{5}$ considera que la pobreza es más que un problema de ingresos. Es un problema multidimensional. Desde el enfoque global de la Fundación, la pobreza expresa una insatisfacción de necesidades, una debilidad en el desarrollo de capacidades y una vulneración de derechos. Esta última relativiza la ciudadanía de las personas, al atentar directamente contra el principio de igualdad y no discriminación.

La comprensión de la pobreza desde la definición anterior es quizá un primer paso necesario para acercarnos con más herramientas al tratamiento periodístico del fenómeno.

\section{Algunos "hechos de la causa"}

En plena "crisis hospitalaria", consecuencia de los altos índices de contaminación que se registran año a año en la capital chilena, se produjo un hecho quizás irrelevante para la audiencia masiva, pero notorio y afortunado para quienes trabajamos en el ámbito social. Un periodista, conductor de un programa de televisión matinal, increpó en vivo y en directo a un reportero que hacía un despacho desde un centro de salud. El tema del día era el colapso de la atención en los servicios públicos de salud y el reportero, luego de entrevistar a un médico del lugar,

\footnotetext{
${ }^{4}$ El método oficial de medición de la pobreza en Chile es el de la Canasta de Necesidades Básicas. La medición se realiza comparando el ingreso per cápita de los hogares con un ingreso mínimo esperado, que ascendía en 2006 a 43.712 pesos mensuales en zonas urbanas. Este cálculo se efectúa a partir de una Canasta de Satisfacción de Necesidades Básicas (CSNB), compuesta por un conjunto acotado de bienes y servicios, que son valorizados a precios de mercado. Al valor total resultante se le denomina Línea de Pobreza (LP). También existe una Línea de Indigencia (LI), cuyo costo se obtiene exclusivamente a partir de los productos alimenticios incorporados a la CSNB. Fuente: Fundación para la Superación de la Pobreza. “Umbrales Sociales 2006. Propuesta para la Futura Política Social”. 2005. ${ }^{5}$ Institución privada de la sociedad civil, con intereses públicos, creada en 1994 como Consejo Asesor Presidencial. Se dedica a formular y proponer políticas públicas para la reducción de la pobreza y realiza intervenciones sociales a través de sus tres programas: Adopta un Hermano, Servicios Comunitarios y Servicio País.
} 
insistentemente descorría la cortina que el personal había instalado para proteger la dignidad de las personas que estaban siendo atendidas en camillas ubicadas en los pasillos. El conductor del programa expresa en cámara su malestar por la situación y pide cortar el despacho. "Si estuvieras en una clínica privada no harías eso", le dice al reportero, y cuestiona el hecho de que se sienta con la libertad de opinar y mostrar a "los pobres" en esa situación.

Situaciones muy similares ocurren con frecuencia en los medios de comunicación nacionales. Los periodistas se sienten con la libertad o sienten que deberían entrar a la casa de los pobres, cuando son protagonistas de la noticia, sin siquiera golpear la puerta. Sin embargo, a la casa de "los ricos" no entran jamás.

Con respecto a este tipo prácticas profesionales en el tratamiento de la pobreza se evidencian avances sobre todo en el lenguaje. Lo que antes era muy común, ahora es extraño, por ejemplo, en la diferencia entre denominar "vecinos" a quienes residen en barrios de mayores recursos y "pobladores" a personas que viven en sectores periféricos de menores recursos. También constatamos la mayor utilización de la frase "persona en situación de pobreza" en desmedro de "persona en condición de pobreza" o simplemente "pobre". Esto último no es menor, pues una situación es siempre algo posible de modificar, algo pasajero. Sin embargo, estar en condición de pobreza remite a una suerte de inherencia del problema de pobreza a un ser humano determinado, cuestión incorrecta desde todo punto de vista.

Con el objetivo inicial de abrir el debate en torno a este tema, hacia finales de 2003 comenzó a gestarse en Chile el proyecto Comunicación y Pobreza, desarrollado por el Hogar de Cristo, la Facultad de Comunicación y Letras de la Universidad Diego Portales y la Fundación para la Superación de la Pobreza, al cual se sumó desde 2006 el Instituto de la Comunicación e Imagen de la Universidad de Chile.

A partir del diagnóstico común de dichas instituciones sobre los efectos sociales que tiene la actividad desarrollada por los medios de comunicación en la persistencia de determinadas nociones de pobreza, es que se toma la decisión de liderar este debate sobre el rol de los medios de comunicación y los periodistas en la superación de la pobreza, en su contribución posible a la integración social y la necesidad de que existan periodistas especialistas en la materia, bien informados y actualizados.

Debido al papel clave que juegan los medios en la sociedad y atendiendo a que constituyen los dispositivos más utilizados por los ciudadanos para acceder a la información actualizada sobre lo que ocurre en Chile y en el mundo, se considera importante generar conocimiento sobre el cómo y cuánto, con respecto al tratamiento de la pobreza y también se opta por invitar a un cambio de mirada. "El diagnóstico común indica que es momento de reflexionar sobre los efectos directos e indirectos que tiene la actividad desarrollada por los medios de comunicación masivos -tales como la televisión, la radio o la prensa escrita- en la persistencia de determinadas nociones del fenómeno de la pobreza, muchas de las cuales, lamentablemente, abundan en aspectos negativos y estigmatizadores. Cuando los esfuerzos de superación de pobreza encuentran ciertos obstáculos socio-culturales, esto último resulta ser un problema. En muchas ocasiones, visiones pre-existentes en la sociedad (como por ejemplo: "los pobres son gente incapaz", "siempre habrá pobres", etcétera) se ven reforzadas por la labor que realizan los medios. Una de las consecuencias de esto es la dificultad por mantener una autovaloración positiva y emprendedora cuando se vive en la pobreza. Otra es el debilitamiento del compromiso de los "no-pobres" para con sus pares "en situación de pobreza", a partir de la equivocada percepción de que la pobreza representa una realidad autoimpuesta",

\footnotetext{
${ }^{6}$ Universidad Diego Portales, Hogar de Cristo, Fundación para la Superación de la Pobreza. "pobre el que no cambia de mirada". Santiago, 2004.
} 
Es así como en el marco del proyecto Comunicación y Pobreza durante 2003 y 2004 se convocó a diversas personalidades del mundo político, social, empresarial, de la publicidad y el periodismo, a reflexionar sobre la temática propuesta y participar en la primera publicación de este proyecto que se denominó "Pobre el que no cambia de mirada", nombre que, siendo una suerte de juego de palabras, invita justamente a cambiar la mirada sobre la pobreza, transformándose en la frase representativa del espíritu del proyecto.

Durante noviembre de 2004 se realizó el primer gran seminario "Comunicación y Pobreza" donde se presentó el libro antes mencionado y un estudio realizado por la Fundación para la Superación de la Pobreza y el Hogar de Cristo en el cual se analizó la percepción de personas y comunidades en situación de pobreza acerca del tratamiento que la televisión hacía del tema. Dicho estudio se denominó "Los pobres y la televisión, una consulta participativa"7.

Asimismo, durante 2005 se analizó cuantitativamente el tratamiento de los temas de pobreza en los noticieros centrales de la televisión abierta a través del estudio "La Pobreza es Noticia", texto que se presentó en otro seminario realizado en noviembre de ese año y que fue patrocinado por el Consejo Nacional de Televisión.

De los resultados de ambas investigaciones es interesante destacar algunos resultados.

En "Los pobres y la Televisión, una consulta participativa" se buscó establecer las percepciones de usuarios y usuarias del Hogar de Cristo y miembros de comunidades rurales que trabajan con el Programa Servicio País de la Fundación para la Superación de la Pobreza, sobre las modalidades en que son representadas las personas en situación de pobreza en la televisión abierta. Se consultó a un total de 1.410 personas de todas las regiones del país, entre agosto y noviembre de 2004, con la metodología de asambleas participativas.

Los objetivos del estudio fueron identificar las principales causas que los consultados atribuyen a representaciones que aparecen para ellos sesgadas o no ajustadas a la realidad y recoger las principales propuestas que plantean los consultados, para mejorar el tratamiento mediático de la problemática de la pobreza.

Una de las preguntas clave del estudio fue: ¿cómo creen ustedes que se muestra a los pobres en la televisión? Y los resultados fueron sorprendentes: un 40,4\% de los consultados estimó que los pobres son mostrados como delincuentes, seguido de un 34,8\% que indicó el atributo drogadictos. Otros resultados predominantes fueron que los pobres son mostrados como sucios y cochinos $(29,8 \%)$, carentes $(24,1 \%)$, mendigos $(21,3 \%)$. Los asistentes a las asambleas tienden así a vincular a los pobres representados en la televisión con categorías sociales estigmatizadas o segregadas. A partir de estos resultados, se puede inferir que los noticieros en particular también representan a los pobres de similar modo, pues como programas que se emiten por televisión abierta, fueron considerados en este estudio. Esta situación es compleja desde la perspectiva de la ética periodística, pues da cuenta de los efectos sociales importantes que conlleva determinado tratamiento en la construcción de la noticia.

En este sentido, es válido preguntarse qué sucede por ejemplo, con respecto a la vinculación que existe en el relato periodístico presente en los medios de la pobreza con temas como la delincuencia, sobretodo la que además se vincula a jóvenes de sectores populares o comunas caracterizadas por tener población en pobreza. "En general, el aspecto físico de los jóvenes que aparecen en las imágenes de los noticieros es el del joven popular, piel oscura, pelo negro, pobre, mal vestido... Habitualmente estas imágenes corresponden a sectores de pobreza de nuestro país, deprivados, donde se observan calles de tierra, viviendas precarias y en mal estado, un entorno gris,

\footnotetext{
${ }^{7}$ Hogar de Cristo, Fundación para la Superación de la Pobreza. Pablo Villatoro. 2004. Disponible en http://www.fundacionpobreza.cl.

${ }^{8}$ Universidad Diego Portales, Hogar de Cristo, Fundación para la Superación de la Pobreza. Catalina Littin, María José Rubio, Victoria Uranga, Guillermo Sunkel, Mauricio Rosenblüth. "La pobreza es Noticia”. Santiago. 2005.
} 
carente de áreas verdes y de infraestructura mínima, con la presencia de niños descalzos...”9. Los vicios que se detectan en el tratamiento de estas temáticas se vinculan a la desesperanza de la representación realizada, puesto que enfrentados a acciones "antisociales" de jóvenes de clase alta, no necesariamente se observan trayectorias exclusivamente negativas de las noticias e incluso es posible que se atribuyan las causas a problemas que verdaderamente "nos involucran a todos", como podría ser el alcoholismo o la drogadicción. También es probable que se visualicen eventuales soluciones cuando se trata de jóvenes de mayores recursos, como por ejemplo, la concurrencia de la familia, el apoyo de adultos responsables u otra situación positiva, que en el caso de contextos de pobreza, no se muestra, sin poder inferir si existe o no.

En el estudio "La Pobreza es Noticia" se analizaron los noticieros centrales de los cinco canales de televisión abierta de la región Metropolitana durante los meses de marzo, abril, mayo y junio de 2005. En total se revisaron 565 noticieros, los cuales contenían más de 11 mil noticias. De éstas, en apenas $471(4,2 \%)$ se encontraron noticias con contenido de pobreza. Este resultado es consistente con los estudios que periódicamente realiza el Consejo Nacional de Televisión, y que "muestran que los noticieros centrales dedican un $47 \%$ de su tiempo al deporte y a hechos delictuales. En cambio, los problemas sociales y ciudadanos como la salud, la educación, el trabajo y la propia pobreza, no superan en conjunto el $15 \%$ del tiempo de las noticias"10.

De las 471 noticias analizadas en profundidad, un 62,4\% eran noticias "asociadas" a la pobreza, esto es, noticias que presentaban contenido de pobreza, pero que estaban centradas en otros temas como educación, salud, vivienda, etc. La asociación, que es la característica predominante en este caso, sugiere que la pobreza es un tema que se "transversaliza" y aparece continuamente en un conjunto mayor de temáticas que hacen noticia.

Otro resultado interesante fue el que se obtuvo al analizar el foco de la noticia, es decir, si éste estaba en sólo la constatación del hecho noticioso, o además se indagaba en las causas y soluciones. Se detectó que más de un $70 \%$ de las noticias sólo constataban, sin abordar causas y soluciones. Este hecho corresponde ciertamente al formato brevísimo de las notas informativas, pero también da cuenta de la labor más investigativa del periodista mientras construye su relato y los énfasis que otorga a su audiencia. En términos más positivos, la investigación arrojó que las noticias tendían a tratar más de una dimensión del problema y mostraron permanentemente una complementariedad en cuanto a opiniones técnicas de expertos y testimonios de los protagonistas de los hechos.

Ahora bien, el resultado más llamativo en términos del tema que nos convoca es el que se obtuvo a analizar las voces que están presentes en el relato periodístico, es decir, quién habla en la nota o reportaje. El "vocero" con más presencia en las noticias corresponde a los propios periodistas autores de la nota o reportaje, con un abrumador $76 \%$. Este insólito resultado se produce, porque los periodistas generalmente opinan o comentan el hecho noticioso o algún aspecto del mismo convirtiéndose en voceros. Este elevado valor permite suponer la existencia de una apuesta editorial al respecto, relacionada con que los periodistas deben o pueden emitir juicios. Situación que es valorable en tanto no se plantea aquí que el periodista deba ser un mero transportador de la noticia, sino que por el contrario, puede elaborar interpretativamente la noticia con la información que recoge para facilitar la comprensión de sus audiencias. No obstante, llama la atención que esto ocurra en noticias centradas o asociadas a la pobreza. ¿Ocurrirá lo mismo con las noticias de economía o política? ¿El periodista también siente la libertad de valorar él mismo las nuevas tasas de interés o el precio del cobre en los mercados internacionales?

\footnotetext{
${ }^{9}$ VERDUGO, Verónica. “Jóvenes populares, medios y exclusión social”. En Perspectiva Alo Octavo. № 13. 2003.

${ }^{10}$ POLITZER, Patricia. Ex presidenta del Consejo Nacional de Televisión. Discurso en apertura del seminario Comunicación y Pobreza 2005. Disponible en sección Enfoques de http://www.comunicacionypobreza.cl.
} 


\section{La distancia con el "otro" Chile}

Durante los hechos de violencia ocurridos en la conmemoración del 11 de septiembre de 2006, más de algún periodista de radio y televisión emitió juicios reveladores. ¡No parecen imágenes de Chile! ¡Ellos no son "víctimas” directas o indirectas del régimen militar! ¡No tienen motivos para sus acciones! ¡Son sólo delincuentes! Dos días después, el Gobierno decidía convocar para la semana siguiente una "Cumbre de Seguridad Interior" en La Moneda. Al mismo tiempo más de 400 estudiantes de periodismo reunidos en el Congreso Nacional asistían al Primer Seminario Regional sobre Comunicación y Pobreza ${ }^{11}$ y analizaban junto a uno de los expositores, el sociólogo Benito Baranda, la pertinencia de convocar también a una "Cumbre del desempleo juvenil".

¿Podemos permitirnos hoy por hoy que ningún periodista haya puesto en jaque a la autoridad con un cuestionamiento como aquél? ¿Acaso no estamos "viendo" la realidad social de nuestro país, o es que no contamos con las herramientas necesarias para hacerlo? Sin duda, el periodista que hubiese realizado tal hazaña, hubiera logrado poner el tema en el tapete con un "golpe periodístico", objetivo final del medio de comunicación. Era muy claro que la conmemoración del golpe militar era una excusa para los protagonistas de los hechos de violencia. El tema de fondo era otro. Ningún medio lo develó.

"Me atrevería a asegurar que el principal desafío que enfrentan los medios y los periodistas en relación con la pobreza es la gran distancia física y sicológica a que nos situamos del problema... El resultado es que, voluntariamente o no, de manera deliberada o no, se produce una grande y grave deficiencia en la cobertura periodística del tema" ${ }^{" 12}$. A partir de esta reflexión del destacado periodista y académico Abraham Santibáñez, es pertinente preguntarnos acerca de qué prácticas cotidianas en el ejercicio de nuestra profesión contribuyen a inhibir el vínculo no sólo con nuestras audiencias, sino que con los protagonistas de los hechos que relatamos. Qué tipo de vínculo establece el periodista con su audiencia más "popular" y cómo mantiene el vínculo con el Chile real es también una cuestión de ética profesional. De otro modo, el quehacer periodístico redundaría en la figura de la "correa transportadora" de información, desde la cima del poder y los intereses de las elites, hacia la archicitada opinión pública.

Las prácticas que inhiben la creación de vínculos entre los pobres y el resto de la sociedad, pueden además mermar el estado de ánimo de las personas que se ven afectadas por la precariedad socioeconómica y generar prácticas institucionales excluyentes. En el momento de juzgar y condenar públicamente a los jóvenes que realizaron acciones de violencia, ¿tuvo el periodista la posibilidad de mirar los hechos desde un punto de vista novedoso y por ende, tener acceso a una herramienta que le permitiera enriquecer su trabajo, cumplir con los objetivos del medio y contribuir con la mejor comprensión ciudadana del fenómeno que ocurría? Le hubiera bastado a ese periodista consultar las cifras de desempleo y verificar que el desempleo en el segmento juvenil supera el $20 \%^{13}$ mientras que el desempleo nacional no llega al $10 \%$. Otras herramientas disponibles eran preguntar a expertos sobre las repercusiones sociales y sicológicas que la exclusión laboral y la falta de acceso a las oportunidades provoca en el segmento, y además, verificar en terreno cómo es el entorno de los protagonistas de los hechos. El resultado de seguro hubiera sido una importante noticia, y a la vez, una decidida contribución a la no discriminación, a la comprensión de la realidad que se vive en sectores marginales de la capital, y finalmente, a que el país y sus autoridades no pudieran eludir su responsabilidad en la rabia que sienten miles de

\footnotetext{
${ }^{11}$ El seminario se realizó en Valparaíso el 13 de septiembre de 2006 en el salón de honor del Congreso Nacional. El director Social Nacional del Hogar de Cristo, Benito Baranda, fue uno de los expositores.

12 SANTIBÁÑEZ, Abraham. "Los medios de comunicación y la pobreza", columna de opinión publicada en Diario Siete, 23 de noviembre de 2005. Disponible en sección Enfoques de http://www.comunicacionypobreza.cl.

${ }^{13}$ Instituto Nacional de Estadísticas (INE). Boletín Informativo Trimestral de Empleo. Septiembre 2006.
} 
jóvenes sin oportunidades, que miran desde la posición más débil a una sociedad cuya desigualdad en la distribución de la riqueza se agudiza y que realizan acciones autodestructivas, pues lo que quemaban y destruían no era más que su propio entorno, sus comercios cercanos, sus teléfonos públicos, sus calles.

Es probable que la contribución posible al ejercicio de los derechos de las personas en situación de pobreza sea la conexión más positiva que pueda establecer el periodista con ese tipo de audiencia. El punto de partida de esta práctica es considerarlos a la hora de informar aunque no sean protagonistas de los hechos y está el entender que es a través de los medios, especialmente de la televisión, que ellos se informan sobre las políticas públicas destinadas a ellos. Esto es una acción de inclusión.

Desde la ética, otra contribución posible del buen periodismo es la no estigmatización. Un ejemplo contrario es lo que presenciamos en un programa de reportajes de un canal de televisión ${ }^{14}$. Una investigación en profundidad, que permitió capturar a los líderes del narcotráfico de la población La Legua. "Los hechos, desde la perspectiva policial, un acierto, periodísticamente nada nuevo, ni por el tema ni por el enfoque. Desde el punto de vista humano, un ejercicio público de vulneración de derechos de comunidades y personas, una acción más que invisibiliza la organización, la superación, el compromiso por hacer de este hostil entorno, un lugar donde vivir" $^{\prime 2}$. Es importante reflexionar sobre las decisiones que los periodistas debemos tomar en la medida que construimos nuestros relatos. Hay decisiones que constituyen juicios y condenas inmediatas y públicas, y es insoslayable tener conciencia de aquello. En el reportaje citado abundan estas disyuntivas y los grandes perjudicados son las personas que habitan en esos lugares.

\section{A modo de conclusión}

La globalización es un fenómeno que se extiende en el mundo y pareciera transversal a las clases sociales. La pobreza y la desigualdad también se extienden, ¿son estos fenómenos igualmente transversales a las clases sociales? Somos parte de la pobreza en tanto contribuimos a las causas que la hacen persistir. La grave segmentación social es un problema de la sociedad toda, pero la vinculación de pobreza con delincuencia por ejemplo, es una actitud personal, alimentada eventualmente por los medios de comunicación.

En la tarea de contribuir a tener ciudadanos mejor informados, más cercanos y concientes de las problemáticas que supone la pobreza, y por qué no, en el fortalecimiento de valores sociales como la participación, la solidaridad y la mejor relación de los ciudadanos con sus pares, con el Estado, los medios tienen mucho que hacer.

El Código de Ética vigente del Colegio de Periodistas señala que los periodistas están al servicio de la verdad, los principios democráticos y los derechos humanos. Si consideramos que la pobreza es en sí misma una situación que vulnera los derechos de las personas, este código de ética nos interpela también al tratar temas de pobreza. A pesar de que el concepto pobreza es variable puesto que depende de cada país, su historia y su realidad, la pobreza es siempre una restricción de la libertad, de ahí que es en sí misma una vulneración de los derechos humanos. A partir de esta premisa básica se inscriben otros males y otros derechos humanos vulnerados que acarrea la situación de pobreza, como la relativización de la ciudadanía, la desigualdad, la discriminación y la estigmatización.

Es quizá en el desafío de la integración social, donde los periodistas chilenos podemos poner en jaque no solamente a la autoridad o a los grupos de poder, sino que a la opinión pública, a

\footnotetext{
${ }^{14}$ TVN. Capítulo "Operación Anastasia” del programa Informe Especial. Emitido el 2 de agosto de 2006.

${ }^{15}$ RUBIO, María José. "Nos internamos en el corazón de La Legua”. Columna de opinión publicada en la sección Enfoques de http://www.comunicacionypobreza.cl.
} 
las audiencias, al revelar aquello que algunos beneficiados del crecimiento y el desarrollo prefieren no mirar.

Situarse desde la posición del que mira la pobreza, en nuestro país, como un asunto escaso y reducido a los beneficiarios de una política social focalizada, es extender la desconexión con las audiencias y finalmente con la sociedad. Más allá del juicio ético y de responsabilidad social en tanto seres humanos y profesionales que han tenido la oportunidad de serlo sería una autocensura, una acción de quitarnos nosotros mismos la posibilidad de encontrar historias dignas de ser contadas, procesos de alto interés público, políticas fracasadas, actuaciones de interés público dudosas, y otras buenas historias. Es cierto que desde 1990 la pobreza se ha reducido a la mitad, según cifras oficiales, pero es cierto también que una sociedad con un desarrollo en ciertos aspectos tan alto, no puede permitirse que exista. Somos los periodistas los primeros que debemos preguntarnos si la sociedad chilena tolerará la existencia de la pobreza o hasta qué punto se soportará tanta desigualdad.

La ética periodística en el tratamiento de la pobreza parte de un ejercicio profesional impecable en cualquier área. En este sentido, aparecen como desafíos el dar más espacio a los temas vinculados a la pobreza, abordarlos con el objetivo de mejorar la comprensión social del fenómeno y sus dimensiones, pero sobre todo prepararse en el conocimiento y las herramientas pertinentes para hacer una labor de excelencia.

Las preguntas aquí tienen que ver con dos lógicas necesarias de atender a la hora de debatir estos temas y de enfrentar "la noticia" asociada a la pobreza. Una tiene que ver con la contribución posible del ejercicio periodístico a la superación de la pobreza y la otra, a mi juicio más importante, vincula al profesionalismo debido en cada ámbito del quehacer de un periodista. No podemos pensar en la consolidación de un periodismo social en Chile sin especialización profesional en las escuelas de pregrado y en estudios posteriores.

Pueden existir muchas miradas con respecto al papel de los medios de comunicación en la superación de la pobreza. Bienvenidas sean, lo importante es que existan y se puedan debatir, pues ese es el principio del fin de las perspectivas reduccionistas y percepciones excluyentes de la pobreza. Lo más importante quizá es comprender que la integración social es el desafío país que tenemos por delante, y que la contribución que hagamos al respecto, provenga de los medios de comunicación o de otro ámbito, siempre suma. 